\title{
Conservation of DNA-binding specificity and oligomerisation properties within the p53 family Tobias Brandt ${ }^{1}$, Miriana Petrovich ${ }^{1}$, Andreas C Joerger ${ }^{1}$ and Dmitry B Veprintsev*2
}

Address: ${ }^{1}$ MRC Centre for Protein Engineering, Cambridge, CB2 0QH, UK and ${ }^{2} \mathrm{MRC}$ Laboratory of Molecular Biology, Cambridge, CB2 0QH, UK Email: Tobias Brandt - tbrandt@mrc-lmb.cam.ac.uk; Miriana Petrovich - mp@mrc-lmb.cam.ac.uk; Andreas C Joerger - acj2@mrclmb.cam.ac.uk; Dmitry B Veprintsev* - dbv@mrc-lmb.cam.ac.uk

* Corresponding author

Published: 23 December 2009

BMC Genomics 2009, 10:628 doi:10.1186/147|-2164-10-628
Received: 26 August 2009

Accepted: 23 December 2009

This article is available from: http://www.biomedcentral.com//47/-2/64/10/628

(C) 2009 Brandt et al; licensee BioMed Central Ltd.

This is an Open Access article distributed under the terms of the Creative Commons Attribution License (http://creativecommons.org/licenses/by/2.0), which permits unrestricted use, distribution, and reproduction in any medium, provided the original work is properly cited.

\begin{abstract}
Background: Transcription factors activate their target genes by binding to specific response elements. Many transcription factor families evolved from a common ancestor by gene duplication and subsequent divergent evolution. Members of the $p 53$ family, which play key roles in cell-cycle control and development, share conserved DNA binding and oligomerisation domains but exhibit distinct functions. In this study, the molecular basis of the functional divergence of related transcription factors was investigated.
\end{abstract}

Results: We characterised the DNA-binding specificity and oligomerisation properties of human $p 53, p 63$ and $p 73$, as well as $p 53$ from other organisms using novel biophysical approaches. All p53 family members bound DNA cooperatively as tetramers with high affinity. Despite structural differences in the oligomerisation domain, the dissociation constants of the tetramers was in the low nanomolar range for all family members, indicating that the strength of tetramerisation was evolutionarily conserved. However, small differences in the oligomerisation properties were observed, which may play a regulatory role. Intriguingly, the DNA-binding specificity of $p 53$ family members was highly conserved even for evolutionarily distant species. Additionally, DNA recognition was only weakly affected by $C_{P} G$ methylation. Prediction of p53/p63/p73 binding sites in the genome showed almost complete overlap between the different homologs.

Conclusion: Diversity of biological function of $p 53$ family members is not reflected in differences in sequence-specific DNA binding. Hence, additional specificity factors must exist, which allowed the acquisition of novel functions during evolution while preserving original roles.

\section{Background}

Sequence-specific transcription factors are responsible for processing environmental and developmental signals, and initiating the appropriate cellular response. The total number of transcription factors of an organism increases with its complexity: it is estimated to be around 300 for yeast, 1000 for worms and 3000 for humans [1]. Besides a DNA-binding domain, another common feature of many transcription factors, such as basic helix-loop-helix (bHLH) factors and basic-region leucine zipper (bZIP) factors, is an additional oligomerisation domain (OD) $[2,3]$. A functional role for oligomerisation is easy to 
rationalize: it combines the DNA-binding specificity of individual monomeric domains, leading to a substantial increase in binding affinity. Divergence of transcription factor function within a family could originate from evolutionary changes in the DNA-binding specificity and in the oligomerisation properties.

A highly important family of transcription factors that play a key role in cell-cycle control and development is that of p53, p63 and p73. p53 is at the centre of a tumour suppressor network $[4,5]$, and, as such, is essential for the prevention of cancer $[6,7]$. Both p63 and p73 are involved in developmental processes. p63 is essential for epidermal morphogenesis and limb development, whereas p73 is involved in the development of neural structures and the pheromone detection system, among its other roles. Nevertheless, p63 and p73 are also involved in processes controlled by p53 [8]. Interestingly, different functions are also observed even for closely related p53 orthologs. For example, genes encoding proteins involved in DNA metabolism are responsive to p53 in humans but not in mice [9]. All three family members consist of a structured DNA-binding domain (DBD), an oligomerisation domain and intrinsically disordered $\mathrm{N}$-terminal transactivation and C-terminal regulatory domains [10]. Additionally, p63 and p73 also contain a structured sterile alpha motif (SAM) and an inhibitory domain at the C-terminus [11]. The majority of cancer-associated p 53 mutations are found in the DNA-binding domain [6,7], highlighting the importance of correct DNA recognition. p53 specifically binds to a 20 base pair (bp) consensus DNA sequence, also called a response element (RE), consisting of two repeats of 5'-RRRCWWGYYY-3' (where $\mathrm{R}=\mathrm{A}$ or $\mathrm{G} ; \mathrm{Y}=\mathrm{C}$ or $\mathrm{T}$; $\mathrm{W}=\mathrm{A}$ or $\mathrm{T})$, separated by $0-13$ bp $[12,13]$. In addition, p53 also recognises a large number of sequences that deviate from this consensus site definition $[14,15]$. Several studies have shown that p53, p63 and p73 can recognise the same sites [16-18]. Additionally, each protein has different isoforms [19], which, in most cases, have identical DNA-binding domains but exhibit differences in transcriptional activity, adding an additional layer of complexity [17].

Despite a high degree of sequence conservation, particularly in the DNA-binding and tetramerisation domains, p53, p63 and p73 fulfil at least partially different roles. The molecular basis of how closely related transcription factors differentiate between their respective target genes is only poorly understood. Here, we characterised the oligomerisation and DNA-binding properties of several p53 family members. Firstly, we determined the dissociation constants for dimers and tetramers of p53 family members using analytical ultracentrifugation. We then compared the DNA-binding specificity of full-length human p53 (Hsp53) with that of its paralogs p63 and p73, including the isoforms $\Delta \mathrm{Np} 63 \alpha, \Delta \mathrm{Np} 63 \beta, \Delta \mathrm{Np} 63 \gamma$, $\Delta \mathrm{Np} 73 \beta$ and an engineered truncated version of p73 containing DNA-binding and parts of the oligomerisation domain only (p73CT, residues 104-383). We also compared the DNA-binding specificity of human p53 with that of its orthologs from a number of species at varying evolutionary distances from humans: mouse (Mus musculus, Mmp53), frog (Xenopus laevis, Xlp53), zebrafish (Danio rerio, Drp53) and fruit fly (Drosophila melanogaster, Dmp53). In these measurements, we included effects of CpG methylation as an additional factor potentially influencing DNA-binding specificity. We used a method for quantification of DNA-binding specificity which we have recently developed $[15,20]$. Using fluorescence anisotropy titrations, we measured the effect of every possible single base pair substitution of a consensus sequence on the affinity of the proteins for DNA. The DNA-binding data were then used to identify putative binding sites within the human genome to assess the impact of the differences in DNA-binding specificity.

\section{Results}

\section{Oligomerisation equilibria}

We have shown previously that full-length human p53 dissociates into dimers at nanomolar concentration, and that oligomerisation is essential for high-affinity DNA binding $[21,22]$. Here, we studied the oligomerisation properties of members of the p53 family, namely Dmp53, Drp53, Hsp53, Mmp53, and Xlp53, as well as human $\Delta \mathrm{Np} 63 \beta$ and $\Delta \mathrm{Np} 73 \beta$. The $\mathrm{p} 63$ and $\mathrm{p} 73$ isoforms contain intact DNA-binding and tetramerisation domains. We used sedimentation velocity analytical ultracentrifugation (SV-AUC) experiments with a fluorescence detection system [23], which allows measurements to be made at low nanomolar concentrations. To specifically incorporate a fluorophore, we expressed proteins with a C-terminal CCPGCC tetra-cysteine tag and labelled them with FlAsHEDT2, an arsenic derivative of fluorescein [24].

The sedimentation profile of Hsp53 at $22.5 \mu \mathrm{M}$ monomer concentration, measured using absorbance detection (data not shown), showed only one peak at $\sim 2.9$ S, which we assigned to a tetramer, because the protein has been shown to be tetrameric at this concentration [22]. Subsequently, we measured the sedimentation profiles of labelled proteins at different concentrations using the fluorescence detection system (Figure 1 and Additional file 1 ). At lower concentrations, a second peak appeared at 1.8 to $2.0 \mathrm{~S}$. In order to improve the resolution of the sedimentation profiles in the range between 0.5 and $3 \mathrm{~S}$, we repeated our experiments at higher rotor speeds $(60 \mathrm{k}$ $\mathrm{rpm}$ ). In addition to the tetramer peak, we were able to resolve two peaks at $1.1 \mathrm{~S}$ and $1.9 \mathrm{~S}$, which correspond to monomers and dimers, respectively. 
A

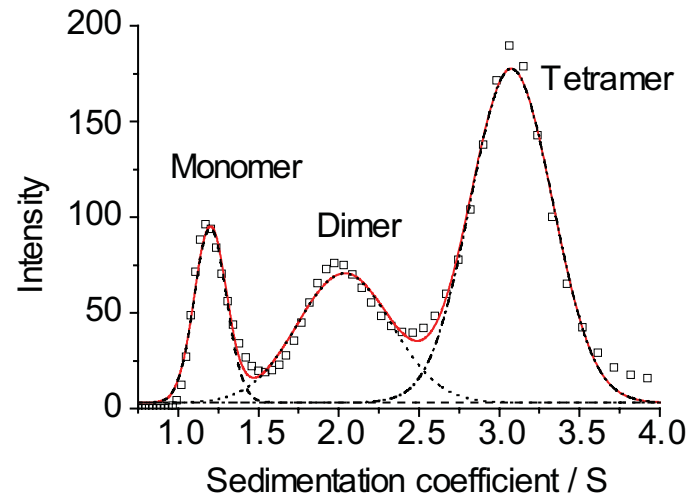

B

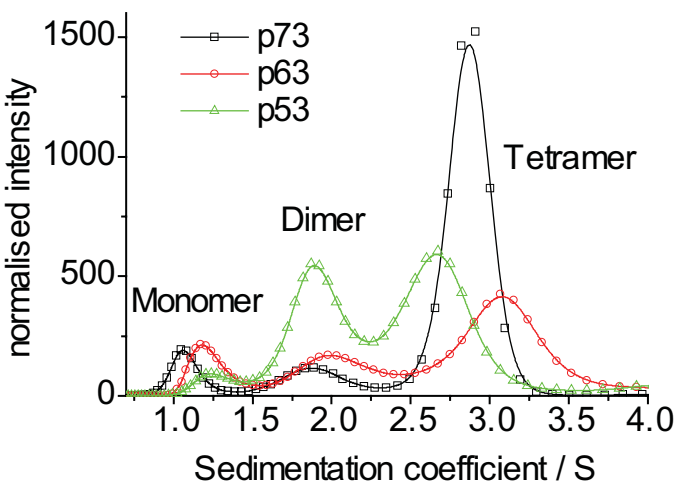

Figure I

Sedimentation profiles measured by fluorescence detection ultracentrifugation. A) Exemplary fitting of data $(\triangle \mathrm{Np} 63 \beta, 50 \mathrm{nM}$, squares) to three normal distributions indicated by dashed (monomer), dotted (dimer) and dash-dotted lines (tetramer). The overall fit is indicated by the red line. B: Comparison of sedimentation traces for human p53 (triangles, green line), $\Delta \mathrm{Np} 63 \beta$ (circles, red line) and $\Delta \mathrm{Np} 73 \beta$ (squares, black line) at a concentration of $50 \mathrm{nM}$ (monomer). Intensities are normalised to the total integrated area.

All proteins studied formed tetramers which dissociate into dimers. For some proteins, these dimers dissociated into monomers. It was possible to determine their sedimentation profiles with well-resolved peaks, and thus to calculate the dissociation constants $K_{\mathrm{d}}$ for the monomerdimer and dimer-tetramer equilibria (Additional file 2, Figure 2). The dissociation constants for the dimertetramer equilibria of Dmp53, Drp53 and $\Delta \mathrm{Np} 73 \beta$ were

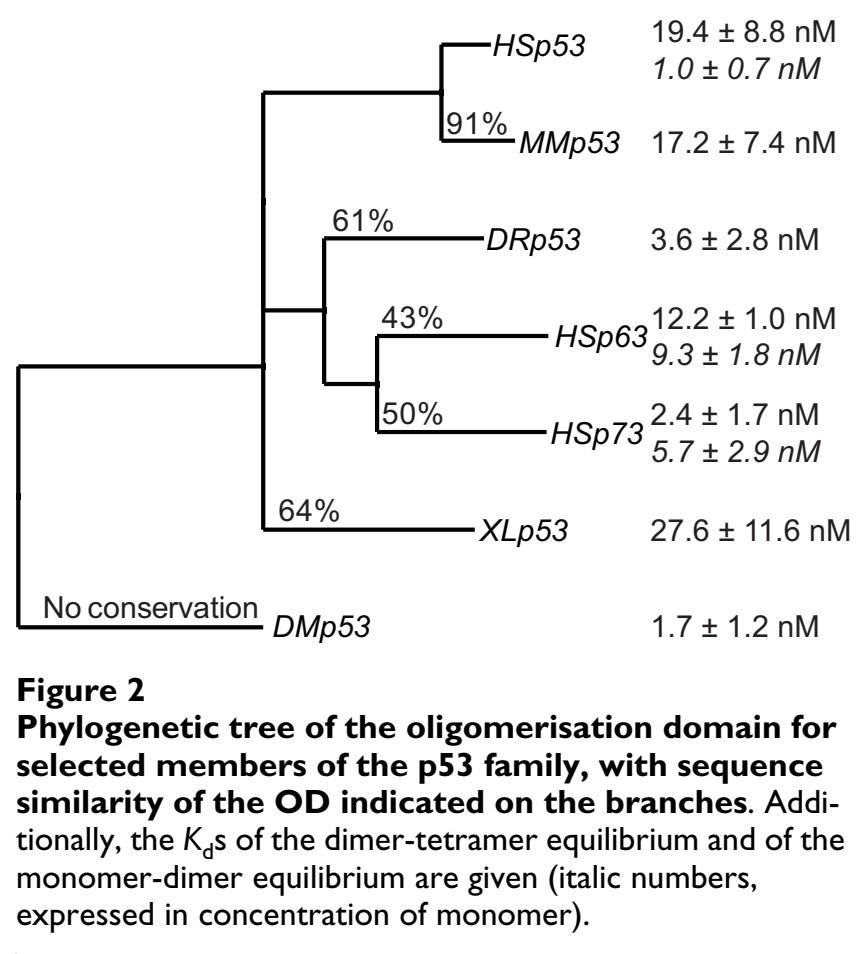

in the low nanomolar range. The self-association was about 5 times weaker for $\Delta \mathrm{Np} 63 \beta$ and about 10 times weaker for Mmp53, Hsp53 and Xlp53. At low nanomolar concentrations, tetramers of human p53 dissociated into dimers, whereas those of human p63 and p73 readily dissociated into dimers and monomers. In the case of p63, the dissociation constants for momomer-dimer and dimer-tetramer equlibria were similar. For p73, the dimermonomer $K_{\mathrm{d}}$ was even larger than the dimer-tetramer $K_{\mathrm{d}}$. This indicates that only small amounts of p73 dimers are present in solution. For human p53, this is not the case, as the monomer-dimer $K_{\mathrm{d}}$ is about 20 times lower than the dimer-tetramer $K_{\mathrm{d}}$. No monomers were observed for Dmp53 and Drp53.

\section{DNA-binding specificity of $p 53$ family members is highly conserved}

It is often assumed that diverging transcription factors have differences in their DNA-binding specificity, which result in preferential recognition of a different response element sequence and an associated change in function. To answer the question of whether the $\mathrm{p} 53$ response element sequence is evolving and diverging, we compared the DNA-binding specificity of human p53, p63 and p73, and $\mathrm{p} 53$ from different species. We used a fluorescence anisotropy assay, which we had developed earlier for quantifying the DNA-binding specificity of Hsp53 $[15,21]$.

First, the $K_{\mathrm{d}}$ between fluorescently labelled DNA and protein was measured using direct titrations (Figure 3A). Data were analysed using the Hill equation. The measured $K_{\mathrm{d}}$ values were similar for all proteins studied (Table 1 ), and 
A

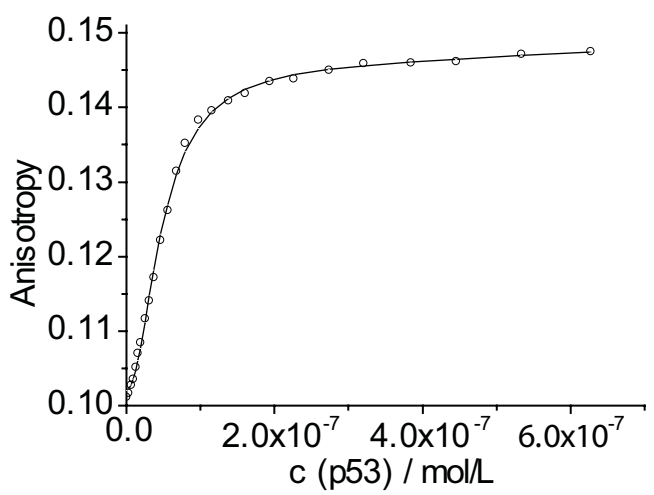

B

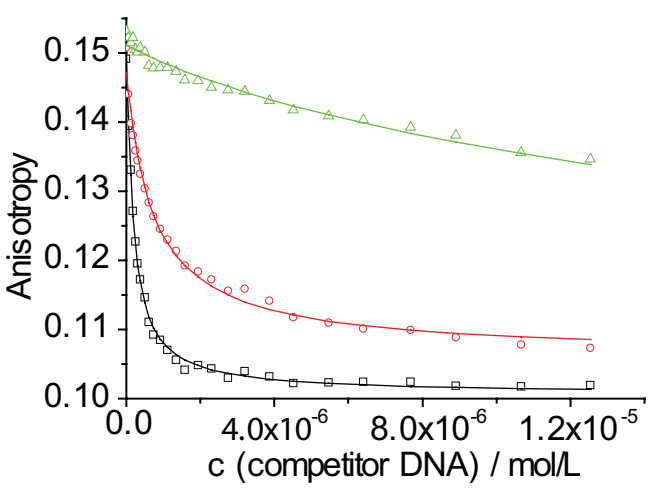

Figure 3

Anisotropy titration assay. A) Typical direct titration curve of a solution of I.25 $\mu$ M Xlp53 titrated into 20 nM labelled Ref_Alexa488. Measured anisotropy values were fitted to a Hill equation allowing the calculation of the dissociation constant $K_{d}$ for the binding event between the labelled DNA and the protein. B) Displacement of a labelled reporter oligonucleotide from the complex by an unlabelled competitor oligonucleotide, reflected by a decrease in the anisotropy, allows accurate measurement of the difference in the $K_{d}$ between two sequences. Shown are typical titration curves for a competition experiment, in this case XIp53: a $50 \mu \mathrm{M}$ solution of competitor DNA was titrated into a solution of $20 \mathrm{nM}$ labelled DNA and $400 \mathrm{nM}$ Xlp53. Measured anisotropies are shown for a tight (Ref, log $K_{d}=-7.08$, squares, straight line), an average $\left(A 5 G, \log K_{d}=-6.64\right.$, circles, dashed line) and a weak $\left(G 7 C, \log K_{d}=-5.70\right.$, triangles, dotted line) binding sequence with corresponding fits.

observed differences were within the error range of the method. The only exception was p73CT, which bound about 4-5 times more weakly than the $\Delta \mathrm{Np} 73 \beta$ isoform. Weaker binding of p73CT can be attributed to impaired self-oligomerisation due to a truncation of the tetramerisation domain, which has been shown to destabilise the tetramer [25]. The Hill coefficient $n$ was averaged over all measured datasets $(n=1.64)$, which was in close agreement with the value we have previously reported for human p53 [22]. In combination with analytical ultracentrifugation data, we can conclude that for all the proteins studied two dimers bind DNA cooperatively and form a tetramer, similarly to human p53 [21].

The driving force for recognition of a specific DNA sequence surrounded by non-specific seqences is not the absolute affinity but rather specificity, or the relative affinity for specific vs. non-specific sequences. To define the DNA-binding specificity of the members of the p53 family, we measured the affinity of the proteins to all possible permutations of a reference consensus binding sequence (Additional file 3) using a fluorescence competition titration assay (Figure 3B). This sequence contains two identical copies of a GGACATGTCC half-site and is one of the tightest-binding sequences for human p53 [15]. The results for all the p53 homologs analysed are summarised in Figure 4. For every nucleotide substitution, the difference of the logarithm of the dissociation constants for the mutated sequence and the reference sequence $\left(\Delta \log K_{\mathrm{d}}\right)$ was determined. High positive values of $\Delta \log K_{\mathrm{d}}$ indicate high affinity penalties and low probability of observing this substitution in the binding site. The effects of nucleotide substitution are also presented as a sequence logo (Figure 5), which depicts the most preferred nucleotide at a position as the largest letter, and the relative selectivity at this position as the height of the bar. Based on the affinity differences, we calculated expected relative nucleotide frequencies for each position, and a corresponding bit score ranging from 0 to 2 [26,27]. Key features of the response element are highly conserved between all the proteins studied. The largest decrease in affinity was caused by nucleotide changes at positions 4 and 7, which correspond to the invariant $\mathrm{C}$ and $\mathrm{G}$ in the RRRCWWGYYY consensus sequence. Nucleotide changes at positions 5 and 6 , corresponding to the central WW element, and positions 3 and 8 , also caused significant changes in the affinity. Generally, changes at the outer positions 1, 2 and 9, 10 did not significantly affect binding. Accordingly, the largest contributions to the overall DNA-binding specificity are made by positions 4 and 7, followed by 3, 5, 6, and 8 . The observed changes can be alternatively expressed as a consensus sequence definition (Table 1). Selecting the nucleotide changes resulting in the highest affinity at each position defines the highest affinity sequence. A better reflection of DNA-binding specificity is to apply a cut-off value representing the error of the measurement. All nucleotides at a particular position that cause a lower affinity change, $\Delta \log K_{\mathrm{d}}$, than the cut-off value are treated as having equal binding properties. Depending on the cut-off value, a number of different nucleotides can be present at a given position. For example, Dmp53 recognises the highest affinity sequence GAACATGTCC, which 
Table I: DNA-binding parameters of $\mathrm{p} 53$ orthologs and paralogs.

\begin{tabular}{|c|c|c|c|c|c|}
\hline Protein ${ }^{a}$ & $\begin{array}{l}\log K_{d}(\text { direct) } \\
\text { GGACATGTCC } b, c\end{array}$ & $\begin{array}{l}\log K_{d} \text { Ref } \\
\text { (competition)d }\end{array}$ & $\begin{array}{l}\text { Tightest binder } \\
\log _{d} K^{e}\end{array}$ & $\begin{array}{l}\text { Consensus sequence using a } \Delta \log K_{d} \\
\text { cut-off of } 0.1 \text { and } 0.2 f\end{array}$ & $\begin{array}{l}\text { Bit Score } \\
\mathrm{g}\end{array}$ \\
\hline Dmp53 & $-7.28 \pm 0.03$ & -7.56 & $\begin{array}{l}\text { GAACATGTCC } \\
-7.58\end{array}$ & $\begin{array}{l}\text { NRACATGTMB } \\
\text { NDACRTGTHN }\end{array}$ & 10.3 \\
\hline Drp53 & $-7.20 \pm 0.03$ & -7.42 & $\begin{array}{l}\text { GGGCATGCCC } \\
-7.59\end{array}$ & $\begin{array}{l}\text { RRRCATGCCY } \\
\text { VRRCATGYCB }\end{array}$ & 13.1 \\
\hline Hsp53 & $-7.25 \pm 0.03$ & -7.12 & $\begin{array}{l}\text { AGACATGTCC } \\
-7.14\end{array}$ & $\begin{array}{l}\text { RRRCWTGYCY } \\
\text { NDRCWWGYCY }\end{array}$ & 8.8 \\
\hline Mmp53 & $-7.02 \pm 0.04$ & -6.88 & $\begin{array}{l}\text { GGACATGCCC } \\
-6.94\end{array}$ & $\begin{array}{l}\text { VRRCWTGYYY } \\
\text { NDRCWWGYYN }\end{array}$ & 6.2 \\
\hline XIp53 & $-7.32 \pm 0.02$ & -7.08 & $\begin{array}{l}\text { AGACATGTCC } \\
-7.13\end{array}$ & $\begin{array}{l}\text { VRRCATGYCY } \\
\text { NDRCWWGYCY }\end{array}$ & 10.9 \\
\hline$\Delta \mathrm{Np} 63 \alpha$ & $-7.12 \pm 0.01$ & -7.21 & $\begin{array}{l}\text { AGGCATGTCC } \\
-7.37\end{array}$ & $\begin{array}{l}\text { NDRCDWGYCH } \\
\text { NNRCDDGYHN }\end{array}$ & 7.2 \\
\hline$\Delta \mathrm{Np} 63 \beta$ & $-7.13 \pm 0.04(6)$ & -7.45 & $\begin{array}{l}\text { GGGCATGTCC } \\
-7.46\end{array}$ & $\begin{array}{l}\text { NRRCATGTCY } \\
\text { NRRCRWGYCN }\end{array}$ & 12.0 \\
\hline$\Delta \mathrm{Np} 63 \gamma$ & $-7.17 \pm 0.02$ & -7.48 & $\begin{array}{l}\text { GGACATGTCC } \\
-7.48\end{array}$ & $\begin{array}{l}\text { NRRCATGTCB } \\
\text { NRRCRWGYCN }\end{array}$ & 12.7 \\
\hline$\Delta \mathrm{Np} 73 \beta$ & $-7.26 \pm 0.02$ & -7.62 & $\begin{array}{l}\text { CGGCATGTCT } \\
-7.89\end{array}$ & $\begin{array}{l}\text { VRGCATGYCY } \\
\text { NRGCAWGYCB }\end{array}$ & 14.5 \\
\hline P73CT & $-6.62 \pm 0.04(6)$ & -6.83 & $\begin{array}{l}\text { GGGCATGTCC } \\
-7.03\end{array}$ & $\begin{array}{l}\text { NRGCATGYCY } \\
\text { NRRCAWGYCN }\end{array}$ & 13.2 \\
\hline
\end{tabular}

aFull-length proteins of p53 (Dm = Drosophila melanogaster, $\mathrm{Dr}=$ Danio rerio, $\mathrm{Hs}=$ Homo sapiens, Mm $=$ Mus musculus, $\mathrm{XI}=$ Xenopus laevis) and naturally occurring isoforms of human $\mathrm{p} 63$ and $\mathrm{p} 73$ were used. By contrast, $\mathrm{p} 73 \mathrm{CT}$ is not naturally occurring and comprises p73 residues $104-383$. bDouble stranded labelled reporter DNA (Alexa488-GGACATGTCCGGACATGTCCf)

'Each direct titration experiment was repeated 16 times, if not otherwise indicated after the standard deviation (SD) in brackets dDouble stranded unlabelled reference DNA GGACATGTCCGGACATGTCC

eDeviations from the reference sequence are shown in bold letters

$\mathrm{f} N=$ any nucleotide, $\mathrm{D}=\mathrm{A}, \mathrm{G}$ or $\mathrm{T} ; \mathrm{R}=\mathrm{G}$ or $\mathrm{A} ; \mathrm{M}=\mathrm{A}$ or $\mathrm{C} ; \mathrm{B}=\mathrm{G}, \mathrm{C}$ or $\mathrm{T} ; \mathrm{H}=\mathrm{A}, \mathrm{C}$ or $\mathrm{T} ; \mathrm{W}=\mathrm{A}$ or $\mathrm{T} ; \mathrm{Y}=\mathrm{C}$ or $\mathrm{T} ; \mathrm{V}=\mathrm{A}, \mathrm{C}$ or $\mathrm{G}$ gFor bit score explanation see figure 4 .

becomes NRACATGTMB at a cut-off value of $0.1 \log K_{\mathrm{d}}$ units, and NDACRTGTHN at $0.2 \log K_{\mathrm{d}}$ units, where $\mathrm{N}=$ any nucleotide; $\mathrm{R}=\mathrm{G}$ or $\mathrm{A} ; \mathrm{M}=\mathrm{A}$ or $\mathrm{C} ; \mathrm{B}=\mathrm{G}, \mathrm{C}$ or $\mathrm{T} ; \mathrm{H}=$ $\mathrm{A}, \mathrm{C}$ or $\mathrm{T}$; and $\mathrm{W}=\mathrm{A}$ or $\mathrm{T}$. As was shown for human $\mathrm{p} 53$ $[14,15]$, the observed DNA-binding specificity for all the proteins studied is less stringent than the originally proposed definition of the $\mathrm{p} 53$ consensus sequence RRRCWWGYYY [12].

Despite the overall similarities of the DNA-specificity profiles, there are also some notable differences. The magnitude of the penalties with respect to the $\Delta \operatorname{logKd}$ associated with nucleotide changes and the corresponding contribution to the overall specificity of binding varies for different proteins. Both mammalian (human and mouse) p53 proteins, which had the lowest bit score (Table 1), showed the lowest specificity. Evolutionarily more distant verte- brate proteins (zebrafish Drp53 and frog Xlp53) exhibited a selectivity pattern very similar to the mammalian proteins but showed higher bit score values of 10.8 and 12.8 . Approximately 40 to $50 \%$ of the overall specificity came from positions 4 and 7 . These positions were even more important for human p63 and p73 and invertebrate p53 (Dmp53), because they contributed 50 to $70 \%$ to the overall specificity. It is interesting to note that while most proteins prefered the $\mathrm{C}(\mathrm{A} / \mathrm{T})(\mathrm{T} / \mathrm{A}) \mathrm{G}$ motif at the centre of the half-site, p63, p73 and Dmp53 had a slight preference for $\mathrm{G}$ compared to $\mathrm{T}$ at position 5 , recognising the motif $\mathrm{C}(\mathrm{A} / \mathrm{G})(\mathrm{T} / \mathrm{A}) \mathrm{G}$ or $\mathrm{C}(\mathrm{A} / \mathrm{G} / \mathrm{T})(\mathrm{T} / \mathrm{A}) \mathrm{G}$, depending on the selected cut-off. This observation resonates with findings of Osada et al. that p63 preferentially recognises RRRCGTGYYY [17], although A at position 5 resulted in stronger binding in our experiments. The other interesting feature is that p73 favoured G over A in position 3. This is in con- 

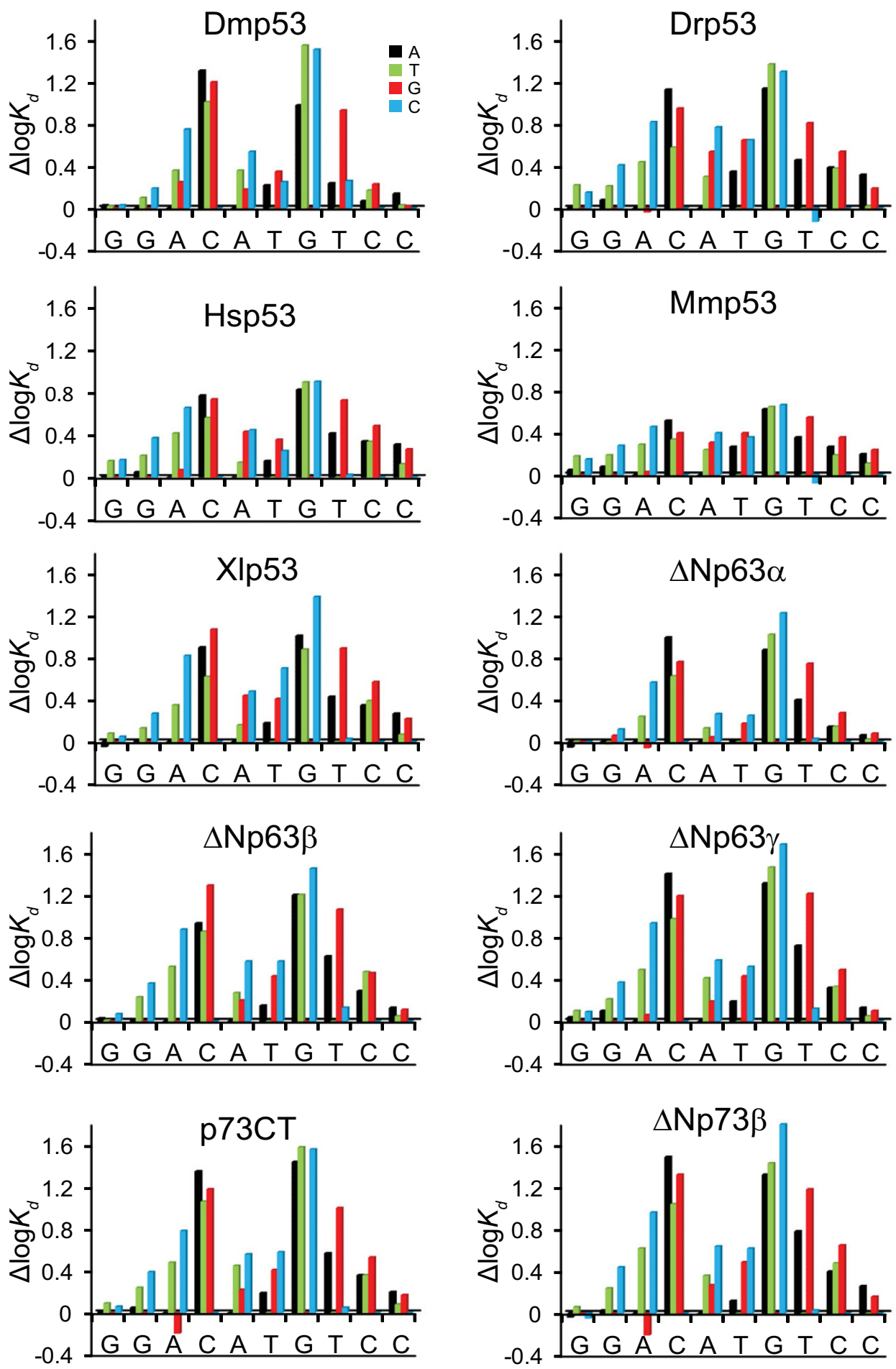

Figure 4

DNA-binding specificity of p53 family members. $\Delta \log K_{d}$ plot for all competitor DNA sequences. Affinity penalties with respect to the reference sequence caused by base pair substitutions are shown for all nucleotides $(A=b l a c k, T=$ green, $G=$ red, $C=$ blue). The reference sequence is indicated below the axis. Only the analysed half-site is shown. A positive value indicates weaker binding of the competitor sequence than the reference sequence, whereas a negative value indicates that the substitution leads to tighter protein-DNA binding. 

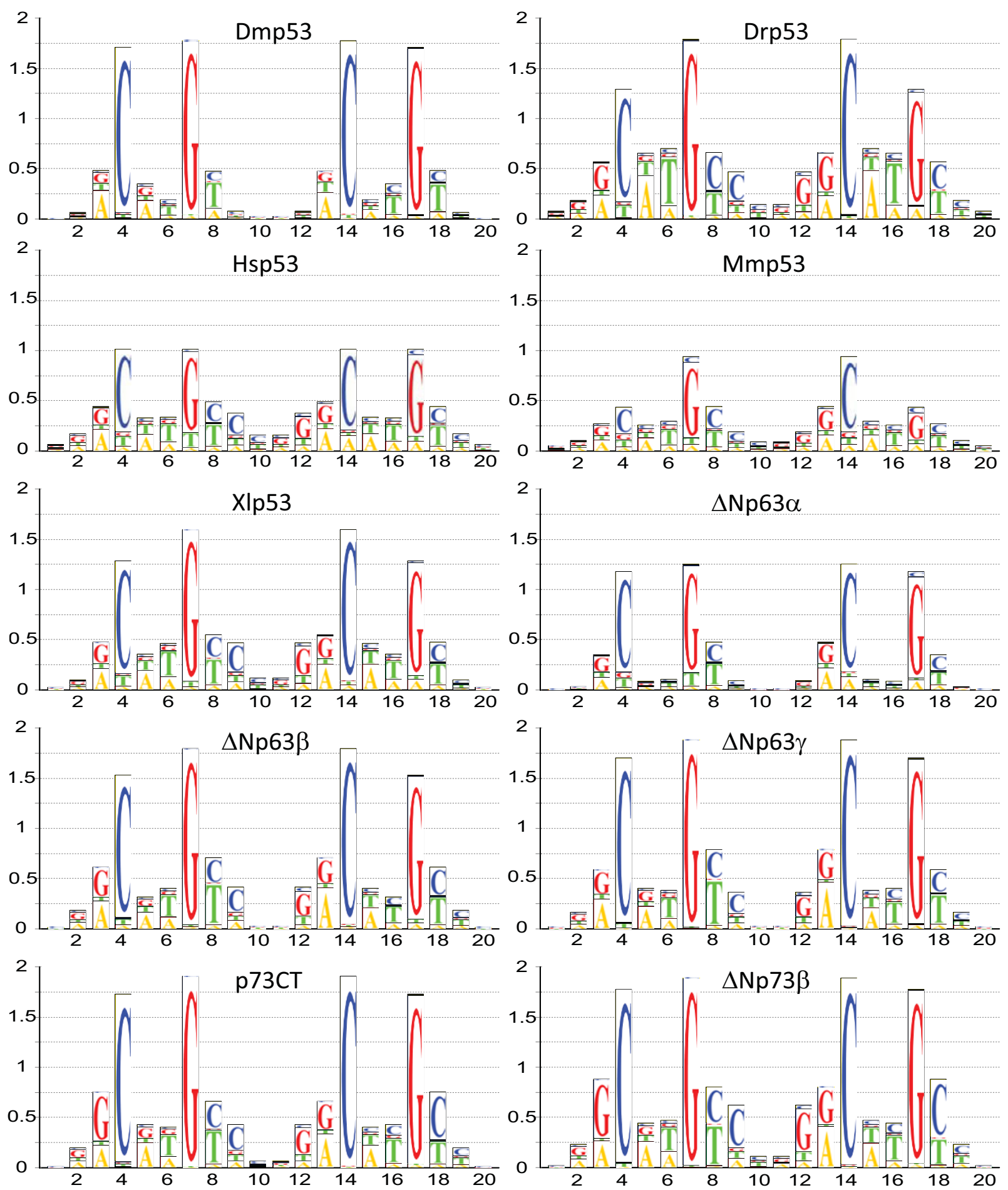

Figure 5

Sequence logos for all p53 family proteins studied. The complete response element is shown, and bit values are plotted against sequence position. A value of 0 means all four nucleotides bind with the same affinity and there is no selectivity, whereas the value 2 stands for absolute selectivity for one nucleotide, with the other three being highly penalised. A measure of the total information content (or selectivity) of the protein can be calculated by summing up all individual bit scores at every position. The maximum theoretical value of information content for a 20 -bp response element is 40 bit. 
trast to findings which suggest an A preceding the CWWG followed by a $\mathrm{T}$ forms the most stable complexes with $\mathrm{p} 73$ [18]. It is worth noting that the overall effects of nucleotide substitutions at positions 3 and 5 were relatively small compared to the effects at the positions 4 and 7.

While the isoforms $\Delta \mathrm{Np} 63 \beta$ and $\Delta \mathrm{Np} 63 \gamma$ behaved almost identically, the isoform $\Delta \mathrm{Np} 63 \alpha$ showed considerably smaller affinity penalties, meaning it is less specific. Interestingly, the DNA-binding affinities in the direct titrations and affinities for the reference sequence in competition experiments were similar for all isoforms. This suggests that the presence of the extreme C-terminal post-SAM domain in $\Delta \mathrm{Np} 63 \alpha$ may affect its DNA-binding specificity. Despite the significantly weaker binding of p73CT compared to $\Delta \mathrm{Np} 73 \beta$ to DNA, the DNA-binding specificity of both $\mathrm{p} 73$ proteins was identical. This suggests that the DNA-binding specificity of tetrameric p73 is determined by the DNA-binding properties of individual DNAbinding domains, whereas the absolute affinity depends on the oligomerisation equilibrium.

\section{DNA methylation does not alter the specificity of p53 family members}

CpG methylation has been shown to affect DNA recognition of transcription factors [28-30]. To investigate the effects of CpG methylation on DNA recognition of p53 family proteins, we used a method that we have previously applied to human p53 [20]. We systematically introduced a CPG dinucleotide at each position in the consensus p53 DNA binding sequence and identified substitutions tolerated by $\mathrm{p} 53$ family proteins. We then compared the binding affinities of methylated versus nonmethylated sequences containing CpG (Additional file 4). Vertebrate p53 proteins (Mmp53, Xlp53 and Drp53) behaved similarly to human p53 and were mildly affected by substitutions at positions 2, 4 and 6 . Interestingly, methylated sequences bound somewhat more tightly than non-methylated, although the effect of a single methylation was small. p63 and p73, along with invertebrate Dmp53, also tolerated CpG nucleotides at these positions. In particular, substitution at position 4 hardly changed the affinity, confirming that the CGTC central element of the binding site is recognised equally well as CATG, which is preferred by $\mathrm{p} 53$.

\section{Computational genome analysis}

Transcription factors recognise a range of sequences which deviate from the highest affinity sequence. As a result of this deviation, the affinity of these sequences can be significantly weaker than that of the highest affinity sequence. We have previously shown that most of the reported p53 binding sites have affinity values up to 1.5 $\log K_{\mathrm{d}}$ units weaker than the highest affinity sequence, and that there is a very large number of potential binding sites in the genome [15]. In this study, the highest affinity sequence was practically identical for all the proteins studied, but the relative penalties for nucleotide substitutions were different. Such differential penalties may result in selection of non-overlapping sets of binding sites by different p53 family members.

To compare the selected sets of the putative binding sites, we computationally predicted all binding sites in the human genome using our affinity data (Additional file 5). We calculated affinity values for every position in the genome (see methods), and selected high-affinity ones using laboratory-developed software. Firstly, we compared the sets of binding sites predicted for human p53, p63 and p73 proteins (Figure 6 and Additional file 6). As we have shown previously for human p53 [15], the number of binding sites increases exponentially with an increasing cut-off value. Since the relative specificity of binding, as reflected by the bit-score value, is higher for p 63 and $\mathrm{p} 73$ than for $\mathrm{p} 53$, there were fewer predicted sites selected at a cut-off value of $1.5 \log K_{d}$ units. We then determined the overlap between the predicted sets of binding sites, taking into account an error of prediction, $e_{\mathrm{p}^{\prime}}$ of $0.35 \log K_{\mathrm{d}}$ units, which we had determined previously for Hsp53 [15]. For almost all proteins, the overlap was $>98 \%$ at cut-off values between 0.5 and $1.5 \Delta \log K_{\mathrm{d}}$. The only exception was Dmp53, which did not show overlap values higher than $68 \%$ with Hsp53. Remarkably,

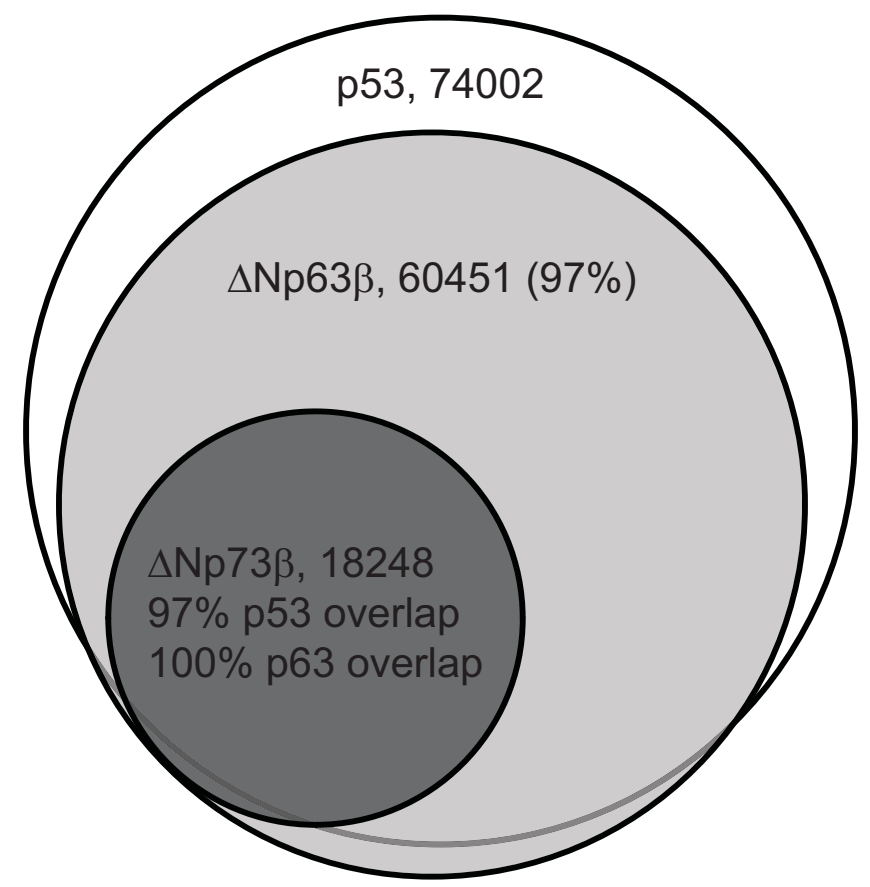

Figure 6

Venn diagram of predicted $p 53, \Delta N p 63 \beta$ and $\Delta N p 73 \beta$ sites in the human genome. 
Dmp53 showed overlaps close to $100 \%$ with $\Delta$ Np63 $\alpha$. Overall, the results of computational analysis suggest that, based on DNA-binding preferences alone, all members of p53 family bind the same set of putative sites in the human genome. The observed quantitative differences in the binding preferences may result in different affinities toward specific binding site sequences, but not in diverging sets of target sites within a given genome.

\section{Discussion \\ Oligomerisation properties of p53 family proteins}

The tetramerisation domain of Hsp53 (residues 325-356) is highly conserved in all vertebrate proteins of the p53 family [31]. A sequence alignment of the tetramerisation domain region of proteins used in this study is shown in Additional file 7. The Hsp53 tetramerisation domain forms a dimer of dimers and is composed of short monomeric building blocks consisting of a $\beta$-strand followed by an $\alpha$-helix [32-34]. The primary dimers are stabilized by an intermolecular $\beta$-sheet and mainly hydrophobic helix packing interactions. In addition, the primary-dimer interface is stabilised by a salt bridge, which is typical for p53 orthologs but not found in its paralogs (Figure 7, Additional file 7). The tetrameric interface is formed by hydrophobic helix packing interactions. The hydrophobic interfaces are largely conserved in all the proteins studied except for Dmp53, which shows no significant sequence conservation and has a dimer-dimer interface that features a cluster of charged residues at its centre [31]. Importantly, recent structural studies have shown that the p73 tetramerisation domain contains an additional C-terminal helix, which is essential for the structural integrity and stability of the tetramer (Figure 7A). This helix is conserved in p63 and presumably has a similar structural role $[25,35]$.

We determined dissociation constants for the monomerdimer and dimer-tetramer equilibria of seven members of the p53 family (Figure 2, Additional file 2). Hsp53, Mmp53 and Xlp53 showed very similar $K_{\mathrm{d}}$ values, consistent with the high conservation of contact residues. p63 and p73 form tighter tetramers than human p53, which, at least in the case of p73, can be attributed to extensive inter-dimer contacts made by the additional C-terminal helix (Figure 7A). Drp53, which, phylogenetically, can be placed somewhere between mammalian p53 and the p63/p73 paralogs [25], also forms more stable tetramers. What is most surprising is that Dmp53 forms tetramers with a comparable $K_{\mathrm{d}}$, while having a completely different dimer-dimer interface, suggesting that, despite structural divergence, the strength of the tetramer has been conserved through evolution.

Interestingly, the primary-dimer interface is tighter in p53 than in p73 (6-fold) and p63 (9-fold). Comparison of the Hsp53 and Drp53 sequences with p63 and p73 suggests
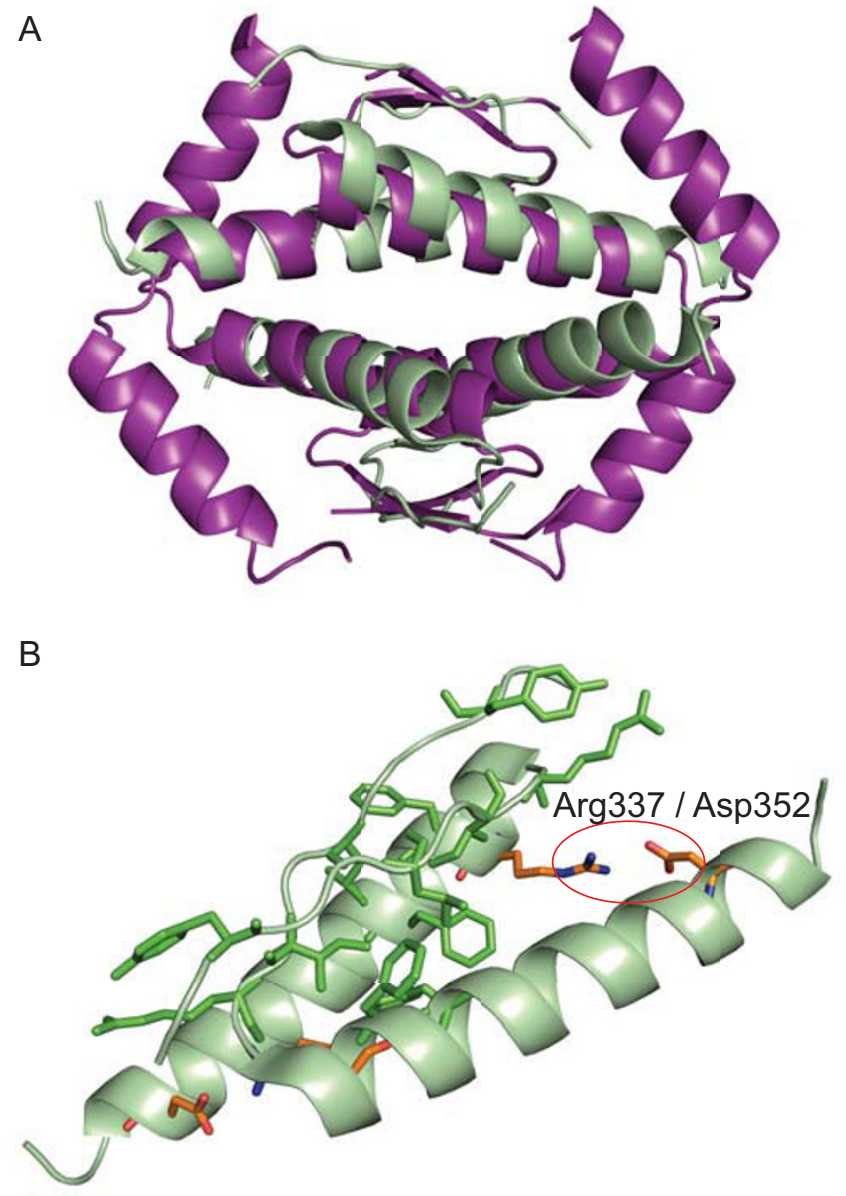

\section{Figure 7}

The tetramerisation domain of human p53 and p73.

A) Superposition of the crystal structures of the tetramerisation domain of human $\mathrm{p} 53$ (green) [57] and human p73 (purple) [25], showing that $p 73$ contains an additional $C$-terminal helix. This helix is conserved in the p63 sister protein. B) Primary-dimer interface of human $\mathrm{p} 53$. The side chains of $Y 327$, L330, I332, R333, F338, L344 (green) and the salt bridge between R337 and D352 (orange) are shown as stick models. The salt bridge is not conserved in human p63 and p73.

that this difference in dimer stability may be attributed to the R337-D352 salt bridge that stabilizes the helix packing in the 553 primary dimer and large-to-small substitutions of hydrophobic residues in p63 and p73. The salt bridge is highly conserved in p53 across different species, and its disruption by a germline mutation $(\mathrm{R} 337 \mathrm{H})$ has been linked with adrenocortical carcinomas in children and other cancer forms [36,37]. p63 and p73 lack this intermolecular salt bridge and have a threonine (p63) and glutamine (p73) instead of the arginine in p53. As a result of the weakened dimer interface in p63 and p73, the dimers formed by tetramer dissociation are more likely to dis- 
sociate directly into monomers. Since key features of the primary dimer interface are highly conserved among different species for each paralog, it is likely that they exhibit dissociation equilibria similar to their human orthologs. The only exceptions are Cavia porcellus and Pteropus vampyrus, whose p53 lacks the paralog-specific salt bridge and may, therefore, also have weakened primary dimers. The observed differences in dissociation equilibria of the human paralogs may have important biological implications for interactions with regulatory proteins, such as members of the S100 family, which have been shown to differentially bind different oligomeric states of p53 $[38,39]$. Taken together, our results show that the overall strength of oligomerisation was conserved during the evolution of members of the p53 family, while subtle differences in the equilibria may play a role in fine-tuning their biological activity.

\section{DNA-contact residues are highly conserved in vertebrates} The sequence identity of the DNA-binding domain of p53 family members varies and is highest between p53 from closely related species, e.g. $86 \%$ identity between mouse and human proteins and $\sim 60 \%$ between Drp53/Xlp53 and Hsp53. Hsp53 makes direct sequence-specific contacts with bases in the major groove of DNA via the side chains of K120, A276, C277 and R280. Contacts with the phosphate backbone are made by the side chains of S241, R248 and R273, and the backbone amides of K120 and A276 $[40,41]$. All DNA-contact residues are conserved in the vertebrate proteins studied (Additional file 8). Upon binding to a DNA half-site, two DBDs form a self-complementary protein-protein interface, mediated by residues P177, H178, R181, M243 and G244, which are conserved in vertebrate p53 [40,41]. In human p63 and p73 ( 60\% sequence identity with Hsp53), however, there are key substitutions in this region, indicating differences in the inter-DBD interactions. Dmp53 shows only $24 \%$ sequence identity to human p53 [42], with significant differences in the various DNA-binding motifs. K120 in the flexible L1 loop of Hsp5 binds to two purine bases in position 2 and 3 of the response element. The equivalent loop in Dmp53 is shortened and more rigid, making it unlikely that the lysine (K102 in Dmp53) forms the same DNA contacts as in Hsp53. In addition, the alanine (A276) making sequence-specific hydrophobic contacts in Hsp53 [40] is replaced by a threonine in Dmp53 (T262). Furthermore, the DNA-backbone contact residue R273 in Hsp53 is replaced by a lysine (K259). The L3 loop, which docks to the DNA minor groove via R248 in Hsp53, is also significantly different. It has a deletion and lacks the equivalent of R249, which plays a key role in stabilizing this region in Hsp53 [43]. Moreover, the L2/L3-loop region that forms the self-complementary DBD-DBD interface also shows variations, similarly to p63 and p73. Taken together, it would be reasonable to expect that the DNAbinding properties of Dmp53 differ from those of Hsp53.

\section{Conservation of the $p 53$ response element and DNA- binding specificity}

We quantified the DNA-binding properties of several members of the p53 family and investigated their ability to recognise methylated DNA. We found that the DNAbinding specificity of both orthologs and paralogs of p53 was conserved. Human and mouse p53 proteins showed almost identical specificity, consistent with their highest sequence conservation. It is also interesting to note that they exhibited the lowest absolute specificity, as reflected by the lowest bit score of the derived motif. Evolutionarily more distant vertebrate p53 proteins (Xlp53 and Drp53) showed a very similar specificity profile but somewhat higher specificity. There seems to be a very interesting underlying correlation: the more complex the organism and the more complex the p53 pathway, the lower the absolute specificity. p63 and p73 showed slightly different DNA-binding specificity compared with p53. This difference may be the result of the different residues in p 63 and p73 being responsible for the interaction between two DBDs upon binding to a half-site motif. Despite the low sequence similarity of Dmp53 and human p53, and their aforementioned differences in key DNA-binding motifs, the DNA-binding specificity of Dmp53 is preserved and is similar to that of vertebrate p53 family members, in particular the more ancestral $\mathrm{p} 63$ and $\mathrm{p} 73$ proteins. The longest p63 isoform tested, $\Delta N p 63 \alpha$, has a significantly reduced DNA-binding specificity compared to other isoforms. It is possible that the additional post-SAM domain present in this isoform is directly or indirectly involved in regulation of its sequence-specific binding.

Using the affinity prediction, we identified all putative binding sites in the human genome for p53, p63 and p73 proteins. Despite quantitative differences in their DNAbinding specificity, all transcription factors studied select overlapping sets of binding sites. We found many more putative binding sites than have been previously identified in genome-wide experiments for p53/p63/p73 proteins [44-46]. The vast majority (95\%) of experimentally identified p53 binding sites [44] contains a site predicted using our affinity data. The published dataset for p63 [45] consists of 5000 sites, which is significantly more than the 1700 sites reported for p53. Less than $20 \%$ of these 5000 sites contain a predicted high-affinity p63 site within a $500 \mathrm{bp}$ window, perhaps reflecting different stringency criteria in peak calling in these two studies. Despite these differences, analysis of all in vivo binding-site sequences in these studies generated positional weight matrices, represented as sequence logos, which are very similar to the sequence logos derived by us based on in vitro binding affinity. This strongly suggests that the driving force for 
localisation of $\mathrm{p} 53 / \mathrm{p} 63 / \mathrm{p} 73$ to their respective sites in the genome is their sequence-specific binding. A recent study using a novel microsphere assay showed that the DNAbinding specificity of endogenous p53 in cell lysate is the same as that of the purified recombinant p53 from our work [47]. Nevertheless, several validated p53 response elements contain non-canonical sequences $[48,49]$. It was shown, that p53 acts weakly to moderately on response elements that contain only a half or a three quarter site of the canonical consensus sequence [50]. This is in accordance with our results, as we observed considerable binding to DNA with a mutated quarter or half site, which de facto represents a non-canonical p53 response element. Binding to non-canonical response elements may be facilitated by co-activating transcription factors. A comprehensive comparison between in vivo and in vitro binding can be found in an excellent recent review [51].

How can transcription factors with virtually identical DNA-binding specificity elicit different biological responses? There is also the closely related question of how transcription factors select their binding site in the genome, among many potential sites of comparable affinity? The "chromatin structure" and "DNA accessibility" concepts may at least partially answer the second question, although the mechanism controlling the chromatin structure with the specificity required is presently unknown. Different expression patterns of transcription factors and/or their abundance in the nucleus can also contribute to their specificity. The involvement of additional specificity factors would answer both questions. Such additional specificity factors should also bind DNA in a sequence-specific manner, and are likely to be transcription factors.

\section{Conclusions}

Taken together, our data show that tetramerisation of p53 family members, which is important for high-affinity DNA binding, was established very early in the evolution of the p53 family and has been functionally conserved ever since. Despite significant differences in the contact surfaces involved, the strength of oligomerisation was preserved. Intriguingly, the DNA-binding specificity of different p53 family members is highly conserved even for evolutionarily distant species. This suggests that original functions were preserved while new functions were acquired during evolution, utilising the same DNA-binding specificity. The "core function" DNA-binding specificity of the p53 transcription factor network did not substantially change during evolution. Instead, there is accumulating evidence that functional divergence of the p53 family evolved through changes in the connectivity within the network, for example by interactions of $\mathrm{p} 53$ family members with different sets of co-activating transcription factors.

\section{Methods \\ Protein cloning}

For human full-length p53 we used wild type protein for DNA-binding experiments and a super-stable mutant, which has four mutations in the core domain (QMHsp53, M133L/V203A/N239Y/N268D) [52,53], for analytical ultracentrifugation experiments. A plasmid encoding Mmp53 was kindly provided by Geoffrey Wahl. Dmp53 was amplified from a cDNA library kindly provided by Simon Bullock. Coding sequences encoding for other studied proteins were amplified from clones obtained from the Mammalian Gene Collection (MGC), distributed via Geneservice (UK). For the $\Delta \mathrm{Np} 63 \gamma$ isoform, parts of the gene were amplified from a genomic DNA library (Geneservice). Additionally, we made a p73 construct containing the DBD and parts of the OD (p73CT, residues 104-383). All inserts were subcloned into a pET24a-HLTEV plasmid containing an N-terminal 6xHis purification tag, a lipoyl domain [54] for improved solubility and a TEV-protease cleavage site. Constructs containing a C-terminal FlAsH-tag CCPGCC [24] were designed in a similar manner.

\section{Small scale expression screening}

Small-scale screening for soluble expression in different cell lines was performed in $2 \mathrm{ml}$ cultures on microplates in 2 XTY media following induction with $1 \mathrm{mM}$ IPTG. Proteins were purified using His-Fusion magnetic beads (BioClone Inc) on a BioSprint15 robot (Qiagen). Purified fractions were analysed by SDS-PAGE pre- and post-digestion with TEV-protease.

\section{Expression and purification}

Large-scale expression and purification was carried out largely as described earlier $[20,22]$. All proteins were overexpressed in E. coli BL21 or B834 cells (Novagen) at $18^{\circ} \mathrm{C}$ for $16-20 \mathrm{~h}$ and purified using standard Ni-affinity chromatography protocols. Subsequently, the $\mathrm{N}$-terminal tags were cleaved off by TEV-protease digestion. As a second purification step for p53 orthologs, heparin affinity chromatography was used. Solutions were diluted to reduce the salt concentration to about $30 \mathrm{mM} \mathrm{NaCl}$. Proteins were eluted using a 20 column volume $\mathrm{NaCl}$ gradient $(0$ to $1 \mathrm{M} \mathrm{NaCl}$ ). The final purification step was gel filtration chromatography using a Superdex 200 16/60 preparative gel filtration column (GE Healthcare) in $225 \mathrm{mM} \mathrm{NaCl}$, $25 \mathrm{mM}$ sodium phosphate $\mathrm{pH} 7.2,10 \%$ glycerol and 5 $\mathrm{mM}$ DTT. Protein purity of $>95 \%$ was determined by SDSgel electrophoresis. Samples were flash frozen in liquid nitrogen and stored at $-80^{\circ} \mathrm{C}$ until used.

\section{Labelling proteins with FIAsH}

Labelling of C-terminally FlAsH-tagged (CCPGCC) proteins [24] was performed in $150 \mathrm{mM} \mathrm{NaCl}, 25 \mathrm{mM}$ phosphate (pH 7.2), $10 \%$ glycerol, and $1 \mathrm{mM} \beta$ - 
mercaptoethanol. $200 \mu \mathrm{L}$ of $10 \mu \mathrm{M}$ FlAsH-tagged protein were incubated with 1.5 equivalents of $\mathrm{FlAsH}_{-} \mathrm{EDT}_{2}$ (Lumio Green, Invitrogen) at $8^{\circ} \mathrm{C}$ for $2.5 \mathrm{~h}$. We estimated that the stock solution was supplied at a concentration of approximately $1 \mathrm{mM}$. Excess label was removed by dialysis into the above buffer. Labelled proteins could be frozen and stored for at least a few months. The labelling reaction could easily be reversed by adding DTT, so care had to be taken to avoid DTT in buffers.

\section{Sedimentation velocity experiments}

We used a XL-I analytical ultracentrifuge (Beckman) equipped with an AVIV fluorescence detection system (AVIV Biomedical). Experiments with C-terminally FlAsH-tagged proteins and unlabelled QM-Hsp53 (using an absorbance detection system) were done in $150 \mathrm{mM}$ $\mathrm{NaCl}, 25 \mathrm{mM}$ phosphate (pH 7.2), 10\% glycerol, BSA ( 0.2 $\mathrm{mg} / \mathrm{mL}$ ) and $1 \mathrm{mM} \beta$-mercaptoethanol at $10^{\circ} \mathrm{C}$. For fluorescence measurements, cells were pre-treated with a concentrated $(1 \mathrm{mg} / \mathrm{ml})$ solution of BSA and allowed to dry before loading samples. Sample volume was $80-90 \mu \mathrm{L}$ at concentrations of 5-500 $\mathrm{nM}$ in SedVel60K fluorescence velocity cells (Spin Analytical). At least 15 measurements were done for each protein. Buffer density and viscosity were calculated using SEDNTERP software. Data analysis to obtain sedimentation coefficient traces was done with SEDFIT software [55]. Since only the tetramer peak at $3 \mathrm{~S}$ was detected in experiments with Hsp53 without the FlAsH-tag, we ignored peaks at higher sedimentation coefficients found for FlAsH-tagged proteins as artefacts caused by cross-linking of oxidised cysteines of the tag. Fitting of sedimentation profiles to normal distributions and $K_{\mathrm{d}}$ calculation was done with our own laboratory software to estimate the relative amount of dimers and tetramers. The reported values for human p53 are somewhat lower than the values we have reported previously [56]. Most likely, a change in the cell design resulting in significantly lower surface area of exposed epoxy material and pre-treatment of the cells with concentrated BSA solution minimised the adsorption of p53 proteins to the cell wall, thereby increasing the fraction of material present in solution.

\section{Fluorescence anisotropy spectroscopy}

All experiments were carried out in 96-well plates using a Pherastar plate reader (BMG Labtech) equipped with a Bravo 96-channel pipetting robot (Velocity 11) as previously described [15]. Buffer conditions for all experiments were $25 \mathrm{mM} \mathrm{NaPi}, 225 \mathrm{mM} \mathrm{NaCl}, 10 \% \mathrm{v} / \mathrm{v}$ glycerol, $5 \mathrm{mM}$ DTT and $0.2 \mathrm{mg} / \mathrm{mL}$ BSA. Titrations were done at $22^{\circ} \mathrm{C}$ and repeated at least three times. Direct titrations were done as previously described [22] using $20 \mathrm{nM} 5^{\prime}-$ Alexa488-GGACATGTCCGGACATGTCC labelled DNA (Operon). The stock solution of $1.25 \mu \mathrm{M}$ protein was titrated in small amounts, which allows calculation of the
$K_{\mathrm{d}}$ for the binding of labelled DNA to protein [21]. For competition experiments, a mixture of protein (at a concentration four times above the $K_{\mathrm{d}}$ value, measured by direct titrations) and $20 \mathrm{nM}$ labelled DNA were used as analytes, and competitor DNA $(50 \mu \mathrm{M})$ was titrated in small steps. Over 3000 titrations were performed in total. Data were analysed according to cooperative binding and competition models using laboratory developed software [15].

\section{Computational search for putative binding sites}

The putative binding sites in the genome were located using p53BindingSite software [15], available at http:// www.mrc-lmb.cam.ac.uk/dbv. In short, the DNA-binding affinity was predicted for each position in the genome using binding affinity positional matrices measured for each protein studied, and positions with predicted affinity higher than the cut-off value were selected. We used human genome release 36.3, zebrafish genome release 10/06/2008 (International Human Genome Sequencing Consortium), fruit fly genome release 5 (The FlyBase Consortium/Berkeley Drosophila Genome Project) and mouse genome release 37 (Mouse Genome Sequencing Consortium). Instead of Xenopus laevis we used the Xenopus tropicalis genome (release 4.1, DOE Joint Genome Institute), as it is complete. We set the gap between both half-sites of the RE to be 0 and 1 .

\section{Authors' contributions}

DBV conceived research; TB, MP and DBV performed experiments, TB, MP, ACJ and DBV analysed and interpreted the results; $\mathrm{TB}$ and $\mathrm{MP}$ prepared figures; $\mathrm{TB}, \mathrm{ACJ}$ and DBV wrote the manuscript. All authors read and approved the final manuscript.

\section{Additional material}

\section{Additional file 1}

Figure S1. Example of raw fluorescence data from analytical ultracentrifugation experiments.

Click here for file

[http://www.biomedcentral.com/content/supplementary/14712164-10-628-S1.PDF]

\section{Additional file 2}

Table S1. Summary of the calculated dissociation constants, observed sedimentation coefficients and protein concentration ranges used in analytical ultracentrifugation experiments.

Click here for file

[http://www.biomedcentral.com/content/supplementary/14712164-10-628-S2.PDF]

\section{Additional file 3}

Table S2. DNA sequences used for anisotropy experiments. Click here for file

[http://www.biomedcentral.com/content/supplementary/14712164-10-628-S3.PDF] 


\section{Additional file 4}

Figure S2. Results of fluorescence anisotropy binding assays using methylated DNA.

Click here for file

[http://www.biomedcentral.com/content/supplementary/1471-

2164-10-628-S4.PDF]

\section{Additional file 5}

Table S3. DNA binding specificity positional weight matrices for $p 53$ family members.

Click here for file

[http://www.biomedcentral.com/content/supplementary/1471-

2164-10-628-S5.XLS]

\section{Additional file 6}

Table S4. Results of computational prediction of putative binding sites within the genome.

Click here for file

[http://www.biomedcentral.com/content/supplementary/14712164-10-628-S6.PDF]

\section{Additional file 7}

Figure S3. Sequence alignment of the tetramerisation domains of the p53 family members.

Click here for file

[http://www.biomedcentral.com/content/supplementary/14712164-10-628-S7.PDF]

\section{Additional file 8}

Figure S4. Sequence alignment of the DNA-binding domains of the p53 family members.

Click here for file

[http://www.biomedcentral.com/content/supplementary/1471-

2164-10-628-S8.PDF]

\section{Acknowledgements}

We thank Caroline Blair for initial cloning experiments and advice in molecular biology as well as Roger Williams, Sarah Teichmann, Caroline Blair and Joel Kaar for critical reading of the manuscript. Discussions about structural properties with Antonina Andreeva proved to be very helpful. TB is supported by Cambridge European Trust and Medical Research Council. This research was supported by Cancer Research UK, the Medical Research Council, and by EC FP6 funding. This publication reflects the authors' views and not necessarily those of the EC. The Community is not liable for any use that may be made of the information.

\section{References}

I. Wilson D, Charoensawan V, Kummerfeld SK, Teichmann SA: DBD-taxonomically broad transcription factor predictions: new content and functionality. Nucleic Acids Res 2008:D88-92.

2. Amoutzias GD, Veron AS, Weiner J, Robinson-Rechavi M, BrnbergBauer E, Oliver SG, Robertson DL: One billion years of bZIP transcription factor evolution: conservation and change in dimerization and DNA-binding site specificity. Molecular biology and evolution 2007, 24(3):827-835.

3. Massari ME, Murre C: Helix-loop-helix proteins: regulators of transcription in eucaryotic organisms. Mol Cell Biol 2000, 20(2):429-440.

4. Vogelstein B, Lane D, Levine AJ: Surfing the p53 network. Nature 2000, 408(6810):307-310.

5. Vousden KH, Lu X: Live or let die: the cell's response to p53. Nat Rev Cancer 2002, 2(8):594-604.
6. Joerger AC, Fersht AR: Structure-function-rescue: the diverse nature of common p53 cancer mutants. Oncogene 2007, 26(I5):2226-2242.

7. Petitjean A, Mathe E, Kato S, Ishioka C, Tavtigian SV, Hainaut $P$, Olivier M: Impact of mutant p53 functional properties on TP53 mutation patterns and tumor phenotype: lessons from recent developments in the IARC TP53 database. Hum Mutat 2007, 28(6):622-629.

8. Moll UM, Slade N: p63 and p73: roles in development and tumor formation. Mol Cancer Res 2004, 2(7):37I-386.

9. Jegga AG, Inga A, Menendez D, Aronow BJ, Resnick MA: Functional evolution of the $p 53$ regulatory network through its target response elements. Proc Natl Acad Sci USA 2008, 105 (3):944-949.

10. Joerger AC, Fersht AR: Structural biology of the tumor suppressor p53. Annual review of biochemistry 2008, 77:557-582.

II. Scoumanne A, Harms KL, Chen X: Structural basis for gene activation by p53 family members. Cancer Biol Ther 2005, 4(I I): I I78-III85.

12. El-Deiry WS, Kern SE, Pietenpol JA, Kinzler KW, Vogelstein B: Definition of a consensus binding site for p53. Nat Genet 1992, I(I):45-49.

13. Funk WD, Pak DT, Karas RH, Wright WE, Shay JW: A transcriptionally active DNA-binding site for human $\mathrm{p} 53$ protein complexes. Mol Cell Biol 1992, I2(6):2866-287I.

14. Tomso DJ, Inga A, Menendez D, Pittman GS, Campbell MR, Storici F, Bell DA, Resnick MA: Functionally distinct polymorphic sequences in the human genome that are targets for p53 transactivation. Proc Natl Acad Sci USA 2005, I 02( I 8):643 |-6436.

15. Veprintsev DB, Fersht AR: Algorithm for prediction of tumour suppressor p53 affinity for binding sites in DNA. Nucleic Acids Res 2008, 36(5): 1589-1598.

16. Schavolt KL, Pietenpol JA: p53 and Delta Np63 alpha differentially bind and regulate target genes involved in cell arrest DNA repair and apoptosis. Oncogene 2007, 26(42):6|25-6I32

17. Osada M, Park HL, Nagakawa Y, Yamashita K, Fomenkov A, Kim MS, Wu G, Nomoto S, Trink B, Sidransky D: Differential recognition of response elements determines target gene specificity for p53 and p63. Mol Cell Biol 2005, 25(14):6077-6089.

18. Lokshin M, Li Y, Gaiddon C, Prives C: p53 and p73 display common and distinct requirements for sequence specific binding to DNA. Nucleic Acids Res 2007, 35(I):340-352.

19. Murray-Zmijewski F, Lane DP, Bourdon JC: p53/p63/p73 isoforms: an orchestra of isoforms to harmonise cell differentiation and response to stress. Cell Death Differ 2006, I3(6):962-972.

20. Petrovich M, Veprintsev DB: Effects of CpG methylation on recognition of DNA by the tumour suppressor p53. J Mol Biol 2009, 386(I):72-80.

21. Weinberg RL, Veprintsev DB, Fersht AR: Cooperative binding of tetrameric $p 53$ to DNA. J Mol Biol 2004, 34 I (5): I I 45-I I 59.

22. Veprintsev DB, Freund SM, Andreeva A, Rutledge SE, Tidow H, Canadillas JM, Blair CM, Fersht AR: Core domain interactions in fulllength p53 in solution. Proc Natl Acad Sci USA 2006, 103(7):2115-2119.

23. MacGregor IK, Anderson AL, Laue TM: Fluorescence detection for the XLI analytical ultracentrifuge. Biophys Chem 2004, 108(I-3): 165-185.

24. Adams SR, Campbell RE, Gross LA, Martin BR, Walkup GK, Yao Y, Llopis J, Tsien RY: New biarsenical ligands and tetracysteine motifs for protein labeling in vitro and in vivo: synthesis and biological applications. J Am Chem Soc 2002, I 24(2I):6063-6076.

25. Joerger AC, Rajagopalan S, Natan E, Veprintsev DB, Robinson CV, Fersht AR: Structural evolution of p53, p63, and p73: implication for heterotetramer formation. Proc Natl Acad Sci USA 2009, 106(42): 17705-17710.

26. Schneider TD, Stephens RM: Sequence logos: a new way to display consensus sequences. Nucleic Acids Res 1990, 18(20):6097-6100.

27. Schneider TD, Stormo GD, Gold L, Ehrenfeucht A: Information content of binding sites on nucleotide sequences. J Mol Biol 1986, I88(3):4|5-43I.

28. Bird AP, Wolffe AP: Methylation-induced repression--belts, braces, and chromatin. Cell 1999, 99(5):45I-454.

29. Jaenisch R, Bird A: Epigenetic regulation of gene expression: how the genome integrates intrinsic and environmental signals. Nat Genet 2003, 33:245-254. 
30. Watt F, Molloy PL: Cytosine methylation prevents binding to DNA of a HeLa cell transcription factor required for optimal expression of the adenovirus major late promoter. Genes Dev 1988, 2(9): I | 36- | |43.

31. Ou HD, Lohr F, Vogel V, Mantele W, Dotsch V: Structural evolution of C-terminal domains in the p53 family. EMBO J 2007, 26(I 4):3463-3473.

32. Jeffrey PD, Gorina S, Pavletich NP: Crystal structure of the tetramerization domain of the p53 tumor suppressor at I.7 angstroms. Science 1995, 267(5203): |498-I502.

33. Clore GM, Ernst J, Clubb R, Omichinski JG, Kennedy WM, Sakaguchi K, Appella E, Gronenborn AM: Refined solution structure of the oligomerization domain of the tumour suppressor p53. Nat Struct Biol 1995, 2(4):32I-333.

34. Lee W, Harvey TS, Yin Y, Yau P, Litchfield D, Arrowsmith $\mathrm{CH}$ : Solution structure of the tetrameric minimum transforming domain of p53. Nat Struct Biol 1994, I( I 2):877-890.

35. Coutandin D, Lohr F, Niesen FH, Ikeya T, Weber TA, Schafer B, Zielonka EM, Bullock AN, Yang A, Guntert P, Knapp S, McKeon F, Ou HD, Dotsch V: Conformational stability and activity of p73 require a second helix in the tetramerization domain. Cell Death Differ 2009, I 6( I 2): I 582-1589.

36. DiGiammarino EL, Lee AS, Cadwell C, Zhang W, Bothner B, Ribeiro RC, Zambetti G, Kriwacki RW: A novel mechanism of tumorigenesis involving $\mathrm{pH}$-dependent destabilization of a mutant p53 tetramer. Nat Struct Biol 2002, 9(I): I2-16.

37. Achatz MI, Olivier M, Le Calvez F, Martel-Planche G, Lopes A, Rossi BM, Ashton-Prolla P, Giugliani R, Palmero El, Vargas FR, Da Rocha JC Vettore AL, Hainaut P: The TP53 mutation, $R 337 \mathrm{H}$, is associated with Li-Fraumeni and Li-Fraumeni-like syndromes in Brazilian families. Cancer Lett 2007, 245(I-2):96-I02.

38. Fernandez-Fernandez MR, Veprintsev DB, Fersht AR: Proteins of the S100 family regulate the oligomerization of p53 tumor suppressor. Proc Natl Acad Sci USA 2005, I 02(I 3):4735-4740.

39. van Dieck J, Fernandez-Fernandez MR, Veprintsev DB, Fersht AR: Modulation of the oligomerization state of $\mathrm{p} 53$ by differential binding of proteins of the S100 family to p53 monomers and tetramers. J Biol Chem 2009, 284(20): |3804-I38II.

40. Kitayner M, Rozenberg H, Kessler N, Rabinovich D, Shaulov L, Haran TE, Shakked Z: Structural basis of DNA recognition by p53 tetramers. Mol Cell 2006, 22(6):74I-753.

41. Cho Y, Gorina S, Jeffrey PD, Pavletich NP: Crystal structure of a p53 tumor suppressor-DNA complex: understanding tumorigenic mutations. Science 1994, 265(5 I 70):346-355.

42. Jin S, Martinek S, Joo WS, Wortman JR, Mirkovic N, Sali A, Yandell MD, Pavletich NP, Young MW, Levine AJ: Identification and characterization of a p53 homologue in Drosophila melanogaster. Proc Natl Acad Sci USA 2000, 97(I 3):730I-7306.

43. Joerger AC, Ang HC, Veprintsev DB, Blair CM, Fersht AR: Structures of p53 cancer mutants and mechanism of rescue by second-site suppressor mutations. I Biol Chem 2005 280(16): I6030-16037.

44. Smeenk L, van Heeringen SJ, Koeppel M, van Driel MA, Bartels SJ, Akkers RC, Denissov S, Stunnenberg HG, Lohrum M: Characterization of genome-wide p53-binding sites upon stress response. Nucleic Acids Res 2008, 36(I I):3639-3654.

45. Yang A, Zhu Z, Kapranov P, McKeon F, Church GM, Gingeras TR, Struhl K: Relationships between p63 Binding, DNA Sequence Transcription Activity and Biological Function in Human Cells. Mol Cell 2006, 24(4):593-602.

46. Wei CL, Wu Q, Vega VB, Chiu KP, Ng P, Zhang T, Shahab A, Yong HC, Fu Y, Weng Z, Liu J, Zhao XD, Chew JL, Lee YL, Kuznetsov VA Sung WK, Miller LD, Lim B, Liu ET, Yu Q, Ng HH, Ruan Y: A Global Map of p53 Transcription-Factor Binding Sites in the Human Genome. Cell 2006, I 24(I):207-219.

47. Noureddine MA, Menendez D, Campbell MR, Bandele OJ, Horvath MM, Wang X, Pittman GS, Chorley BN, Resnick MA, Bell DA: Probing the functional impact of sequence variation on p53-DNA interactions using a novel microsphere assay for proteinDNA binding with human cell extracts. PLoS genetics 2009 , 5(5): el 000462 .

48. Okorokov AL, Orlova EV: Structural biology of the p53 tumour suppressor. Curr Opin Struct Biol 2009, 19(2):197-202.

49. Riley T, Sontag E, Chen P, Levine A: Transcriptional control of human p53-regulated genes. Nat Rev Mol Cell Biol 2008, 9(5):402-4I2
50. Jordan J], Menendez D, Inga A, Noureddine M, Bell DA, Resnick MA: Noncanonical DNA motifs as transactivation targets by wild type and mutant p53. PLoS Genet 2008, 4(6): e l 000104.

5I. Menendez $D$, Inga $A$, Resnick MA: The expanding universe of p53 targets. Nat Rev Cancer 2009, 9(I 0):724-737.

52. Joerger AC, Allen MD, Fersht AR: Crystal structure of a superstable mutant of human p53 core domain. Insights into the mechanism of rescuing oncogenic mutations. J Biol Chem 2004, 279(2): $|29|-\mid 296$.

53. Nikolova PV, Henckel J, Lane DP, Fersht AR: Semirational design of active tumor suppressor p53 DNA binding domain with enhanced stability. Proc Natl Acad Sci USA 1998, 95(25): | 4675-| 4680 .

54. Hipps DS, Packman LC, Allen MD, Fuller C, Sakaguchi K, Appella E, Perham RN: The peripheral subunit-binding domain of the dihydrolipoyl acetyltransferase component of the pyruvate dehydrogenase complex of Bacillus stearothermophilus: preparation and characterization of its binding to the dihydrolipoyl dehydrogenase component. Biochem j 1994, 297(Pt I): $137-143$

55. Schuck P, Perugini MA, Gonzales NR, Howlett GJ, Schubert D: Sizedistribution analysis of proteins by analytical ultracentrifugation: strategies and application to model systems. Biophys J 2002, 82(2): |096-IIII.

56. Rajagopalan S, Jaulent AM, Wells M, Veprintsev DB, Fersht AR: I4-33 activation of DNA binding of p53 by enhancing its association into tetramers. Nucleic Acids Res 2008, 36( I 8):5983-599I.

57. Jeffrey PD, Gorina S, Pavletich NP: Crystal structure of the tetramerization domain of the p53 tumor suppressor at I.7 angstroms. Science 1995, 267(5203): | 498-I 502.
Publish with Biomed Central and every scientist can read your work free of charge

"BioMed Central will be the most significant development for disseminating the results of biomedical research in our lifetime. "

Sir Paul Nurse, Cancer Research UK

Your research papers will be:

- available free of charge to the entire biomedical community

- peer reviewed and published immediately upon acceptance

- cited in PubMed and archived on PubMed Central

- yours - you keep the copyright
BioMedcentral 